\title{
Phlebotomine Sand Flies in Southern Thailand: Entomological Survey, Identification of Blood Meals and Molecular Detection of Trypanosoma spp.
}

\author{
Jirayu Buatong ${ }^{1}$, Vit Dvorak ${ }^{2}$, Arunrat Thepparat ${ }^{3}$, Kanaphot Thongkhao ${ }^{4}$, Surachart Koyadun ${ }^{4}$, \\ Padet Siriyasatien ${ }^{5}(\mathbb{D}$ and Theerakamol Pengsakul $1, *$ (i)
}

\section{check for}

updates

Citation: Buatong, J.; Dvorak, V.; Thepparat, A.; Thongkhao, K.;

Koyadun, S.; Siriyasatien, P.; Pengsakul, T. Phlebotomine Sand Flies in Southern Thailand: Entomological Survey, Identification of Blood Meals and Molecular Detection of Trypanosoma spp. Insects 2022, 13, 197. https://doi.org/ $10.3390 /$ insects13020197 Academic Editor: Corey Brelsfoard Received: 21 November 2021 Accepted: 8 February 2022 Published: 14 February 2022 Publisher's Note: MDPI stays neutral with regard to jurisdictional claims in published maps and institutional affiliations.

Copyright: (C) 2022 by the authors. Licensee MDPI, Basel, Switzerland. This article is an open access article distributed under the terms and conditions of the Creative Commons Attribution (CC BY) license (https:// creativecommons.org/licenses/by/ $4.0 /)$.
1 Faculty of Medical Technology, Prince of Songkla University, Songkhla 90110, Thailand; jirayu.mook@gmail.com

2 Department of Parasitology, Faculty of Science, Charles University, 12844 Prague, Czech Republic; icejumper@seznam.cz

3 Department of Agricultural Technology, Faculty of Science, Ramkhamhaeng University, Hua Mak, Bang Kapi, Bangkok 10240, Thailand; arunratthepparat@gmail.com

4 Office of Disease Prevention and Control, Region 11, Nakhon Si Thammarat 80000, Thailand; kanaphot.t@gmail.com (K.T.); thvbdosk@yahoo.com (S.K.)

5 Vector Biology and Vector Borne Disease Research Unit, Department of Parasitology, Faculty of Medicine, Chulalongkorn University, Bangkok 10330, Thailand; padet.s@chula.ac.th

* Correspondence: theerakamol.p@psu.ac.th; Tel.: +66-7428-9124

Simple Summary: Phlebotomine sand flies (Diptera: Psychodidae) are hematophagous insects, and many species serve as vectors of various human and animal pathogens, including Leishmania and Trypanosoma protozoa. In Thailand, the first case of autochthonous leishmaniasis was reported 62 years ago. At present, the number of human cases is increasing in different regions of the country, but most cases are reported from southern Thailand. Therefore, we studied the potential transmission of Leishmania and Trypanosoma by sand flies in three provinces of southern Thailand, and analyzed blood sources of engorged sand fly females. We detected Trypanosoma sp. DNA in Sergentomyia barraudi, S. indica, S. khawi and Idiophlebotomus asperulus but no Leishmania spp. DNA. Moreover, bloodmeal analysis revealed that Trypanopsoma-positive females of S. barraudi and Sergentomyia sp. fed on dogs and humans, respectively. The results of this study contribute to the knowledge of leishmaniasis and trypanosomiasis presence and sand fly feeding behavior in southern Thailand.

Abstract: An entomological survey at rural and cavernicolous localities in four provinces in southern Thailand provided 155 blood-fed females of sand flies (Diptera: Psychodidae) that were identified based on morphological characters as Idiophlebotomus asperulus $(n=19)$, Phlebotomus stantoni $(n=4)$, P. argentipes $(n=3)$, Sergentomyia anodontis $(n=20)$, S. barraudi $(n=9)$, S. hamidi $(n=23)$, S. hodgsoni $(n=4)$, S. hodgsoni hodgsoni $(n=32)$, S. indica $(n=5)$, S. iyengari $(n=2), S$. khawi $(n=17)$, S. silvatica $(n=11)$ and Sergentomyia sp. $(n=6)$. The dominant species in this study was $S$. hodgsoni hodgsoni, which was collected specifically in a Buddha cave. Screening for DNA of parasitic protozoans revealed eight specimens $(5.16 \%$ ) of four species (S. barraudi, S. indica, S. khawi and Id. asperulus) positive for Trypanosoma sp., while no Leishmania spp. DNA was detected. Blood meals of engorged females were identified by PCR-Restriction Fragment Length Polymorphism (PCR-RFLP) assay on a fragment of cytochrome $b(c y t b)$ gene with a success rate $36 \%$, humans, dogs, and rats being determined as sources of blood. Bloodmeal analysis of two Trypanopsoma-positive females (S. barraudi and Sergentomyia sp.) identified blood from dogs and humans, respectively. Our findings indicate that S. barraudi, S. indica, S. khawi and Id. asperulus may be incriminated in circulation of detected Trypanosoma spp.

Keywords: sand flies; Sergentomyia; Phlebotomus; Trypanosoma sp.; blood meal source 


\section{Introduction}

Phlebotomine sand flies (Diptera: Psychodidae) are hematophagous insects, and many species serve as vectors of Leishmania spp. [1,2] to humans and animals resulting in Leishmaniasis. The DNA of Trypanosoma spp. has also been detected in sand flies [2-4]; however, sand flies have not been incriminated as a Trypanosoma vector. Leishmaniasis is a vectorborne disease that continues to be a major health problem in many regions of the world [5]. In Thailand, four human-infecting Leishmania were reported [6]; Leishmania donovani and L. infantum belong to the long-time known subgenus Leishmania, L. martiniquensis and $L$. orientalis (originally described as L. siamensis) are classified within a newly established subgenus Mundinia [7]. Human diseases caused by these four species show various clinical symptoms, manifested as visceral leishmaniasis (VL), caused by L. donovani, L. infantum, $L$. martiniquensis and L. orientalis [8-11]; cutaneous leishmaniasis (CL), caused by L. donovani, L. infantum, L. martiniquensis and L. orientalis [7,12-14]; and diffuse cutaneous leishmaniasis (DCL) caused by L. infantum, L. martiniquensis and L. orientalis $[10,15,16]$. Since the first imported case in 1960, autochthonous human leishmaniasis has increased to twenty cases [6]. Most of these local human cases were reported in southern Thailand in PhangNga, Satun, Krabi, Trang, Nakhon Si Thammarat, Songkhla, Phattalung, and Surat Thani provinces, highlighting the importance to investigate leishmaniasis prevalence in these regions. Two previous studies detected DNA of L. martiniquensis in S. barraudi, S. gammea and S. iyengari from endemic leishmania area in Trang province, southern Thailand [17,18]. Recently, the novel species L. orientalis was detected from a cutaneous leishmaniasis patient in northern Thailand [7], and L. orientalis has been detected in field-caught S. iyengari in southern Thailand. Although human trypanosomiases caused by species of the genus Trypanosoma have never been reported in Thailand, Trypanosoma evansi and Trypanosoma lewisi, two species that can be transmitted from animals to humans, and were incriminated in rare human infections [19-22], were detected in animals [23,24]. Recently, Trypanosoma sp. DNA was detected in S. khawi and P. stantoni in southern Thailand [2,25]. These findings suggest that sand flies in southern Thailand may be incriminated in transmission of both Leishmania and Trypanosoma protozoans. Although Trypanosoma DNA detection in sand fly species has been reported continuously, the complete information of Trypanosoma life cycle remains uncertain, while the life cycle of Leishmania in sand flies has been suggested as a natural vector of Leishmania [26,27]. However, little is known about the biology and feeding preferences of sand flies that may provide important insight into their transmission cycle and potential reservoir hosts.

Blood meal analyses provide important insight into the dynamics and transmission route of sand fly-borne diseases. The immunological techniques such as enzyme-linked immunosorbent assay (ELISA) were initially deployed to identify sand fly bloodmeals [28,29], later replaced by molecular tools with higher accuracy. The amplification of the $c y t b$ gene using polymerase chain reaction (PCR) technique and subsequent sequencing is currently widely used for blood meal analysis. However, it remains less cost- and time-effective for analysis of field samples in larger field surveys [30]. The PCR-Restriction Fragment Length Polymorphism (PCR-RFLP) of the $c y t b$ gene decreases the cost of the analysis as it does not require the sequencing step and it has been successfully used to identify sand fly blood meals in many endemic regions, including Brazil [31,32] and Spain [33]. However, it has not yet been applied to sand flies in Thailand. The comparison of potential of PCR-RFLP of the $c y t b$ gene and amplification of the $c y t b$ gene using the PCR technique and subsequent sequencing has been studied [33], showing that the PCR-RFLP technique is an efficient and reliable alternative equal to PCR and subsequent sequencing, with lower cost and quicker results. The PCR-RFLP technique is based on amplifying the $c y t b$ gene of the sandflies blood meal, then cleaving by restriction endonuclease enzymes on recognition sites and cleaving on DNA fragments. The cleaved DNA fragment pattern of the $c y t b$ gene could be shown distinguishing between vertebrate species [33]. However, the PCRRFLP technique necessitates the use of two or more restriction enzymes in order to obtain conclusive results [33]. Therefore, this study aimed to identify sources of blood in engorged 
sand fly females to understand their host preferences. In addition, the specimens were also screened for the presence of Leishmania and Trypanosoma DNA.

\section{Materials and Methods}

\subsection{Ethics Statement}

The method for sand fly collecting and specimen preparation in this study was certified by the Institutional Animal Care and Use Committee, Prince of Songkla University, under reference number 2561-10-021.

\subsection{Sand Fly Collection}

Insects were collected at five localities in four provinces of southern Thailand: from four rural settlements in Phang-Nga (site PNA), Satun (site STN1), Songkhla (site SKA), Surat Thani (site SNI) provinces, and one Buddha cave in Satun province (site STN2) (Figure 1), using Center for Disease Control (CDC) light traps (John W. Hock Co., Gainesville, FL, USA) placed 5 to $10 \mathrm{~cm}$ above the ground. Ten traps were deployed at each site monthly in the early rainy season in June and August 2015, and in the late rainy season in January 2015, from sunset to sunrise (6.00 p.m.-6.00 a.m.). Insects were sacrificed with ethyl acetate in a plastic bag. Sand flies were collected from the total catch insects on Petri dishes under a stereomicroscope (Olympus, Tokyo, Japan) and preserved in a 70\% ethanol solution until processing.

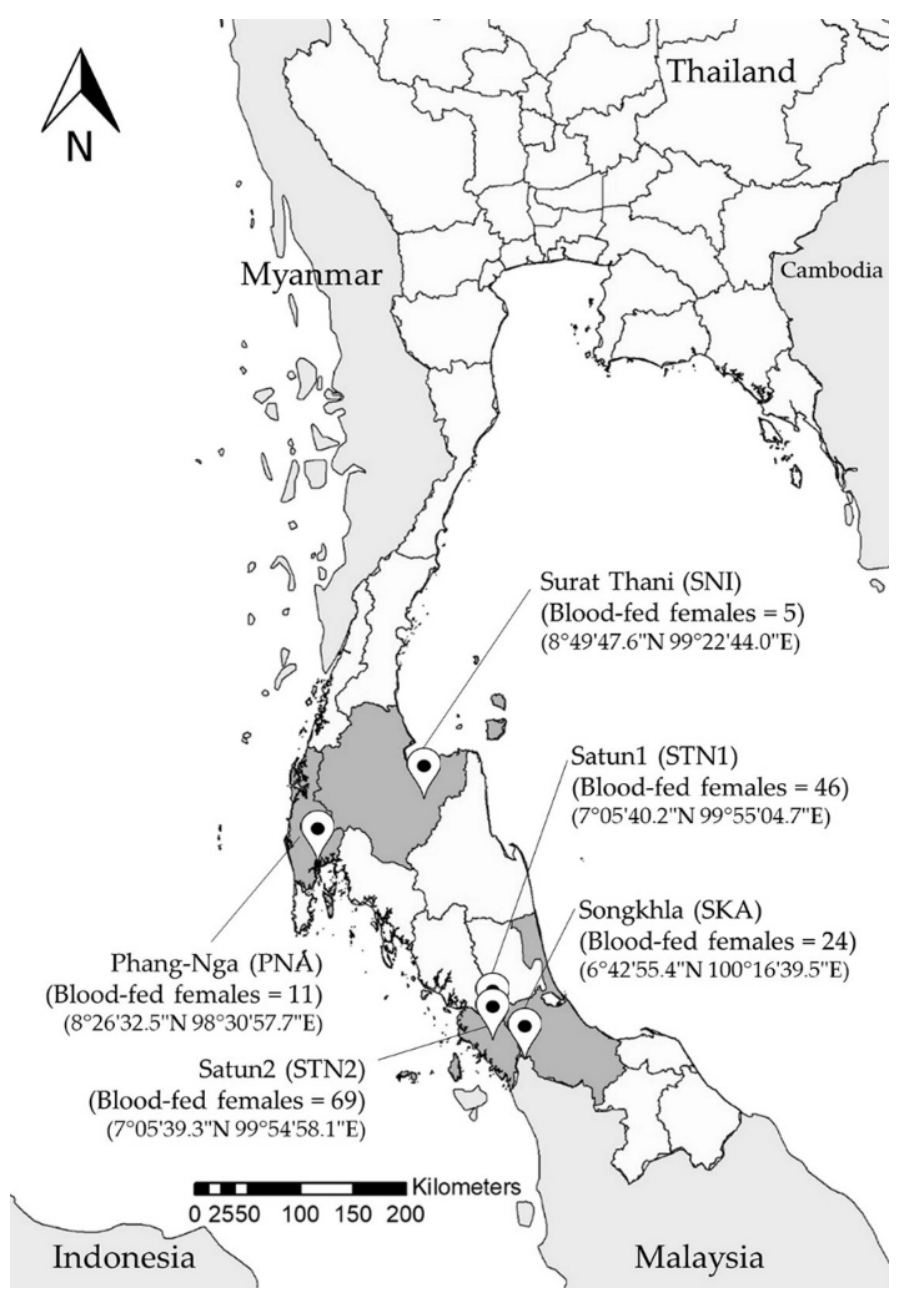

Figure 1. Map of sand fly sampling locations in the south of Thailand with geographic coordinates and the number of collected blood-fed female sandflies at the sites. 


\subsection{Sample Preparation}

Blood-fed sand fly females were selected and placed individually in a $1.5 \mathrm{~mL}$ microtube containing $70 \%$ ethanol. The head of each individual sand fly was dissected on a sterilized glass slide and mounted into Hoyer's medium [34]. The individual thorax and abdomen were transferred to a sterile $1.5 \mathrm{~mL}$ microtube with $70 \%$ ethanol and stored at $-20{ }^{\circ} \mathrm{C}$ for later DNA extraction.

\subsection{Morphological Identification of Sand Flies}

The species of sand flies was identified using taxonomic keys [35-38] based on their species-specific morphological characters of cibarium (shape and color of pigment patch, number of vertical and horizontal teeth) and pharynx under light microscope (Olympus, Tokyo, Japan).

\subsection{Genomic DNA Extraction}

The thorax and abdomen of each sand fly stored in 70\% ethanol were transferred into a new $1.5 \mathrm{~mL}$ microtube, dried at room temperature to remove the remnants of ethanol and homogenized using a disposable polypropylene pestle. The genomic DNA was extracted using the DNeasy Blood and Tissue Kit (Qiagen, Hilden, Germany) according to the manufacturer's protocol, with a final elution by $200 \mu \mathrm{L}$ of elution buffer, and then stored at $-20{ }^{\circ} \mathrm{C}$.

\subsection{Polymerase Chain Reaction (PCR) Analysis and DNA Sequencing}

The concentration of genomic DNA was determined using a NanoDrop 2000c spectrophotometer (Thermo Scientific, Waltham, MA, USA). The cytochrome c oxidase subunit I (COI) gene was amplified using specific primers LepF (5'-ATTCAACCAATCATAAA GATATTGG-3') and LepR (5'-AAACTTCTGGATGTCCAAAAAATCA-3') to obtain the PCR products approximately $658 \mathrm{bp}$ [39] to identify Trypanosoma DNA positive sand flies and confirm the species level. The PCR reaction was performed in a total volume of $25 \mu \mathrm{L}$, containing $10.35 \mu \mathrm{L}$ nuclease-free water, $0.5 \mu \mathrm{L}$ of each primer $(10 \mu \mathrm{M}), 7.65 \mu \mathrm{L}$ of $\mathrm{My} \mathrm{Taq}^{\mathrm{TM}}$ HS Red Mix (BioLine, Taunton, MA, USA) and $6 \mu \mathrm{L}$ of DNA template. The PCR reactions were performed in Eppendorf Mastercycler ${ }^{\circledR}$ Nexus thermal cycler (Eppendorf, Hamburg, Germany) following the published thermal profile as described previously [39]. The PCR products were stained with MaestroSafe TM Nucleic acid loading dye (Maestrogen, Hsinchu, Taiwan), loaded onto a 1.5\% agarose gel and visualized under UV light.

PCR amplification of the internal transcribed spacer 1 (ITS1) region of Leishmania was done using primers LeF (5'-TCCGCCCGAAAGTTCACCGATA-3 $\left.{ }^{\prime}\right)$ and LeR (5'-CCAAGTCA TCCATCGCGACACG-3') [40]. However, this primer set is also complementary to other Trypanosomatidae sequences [40]. Therefore, the amplification of the ITS1 region of Trypanosoma was also performed using this primer set. The total volume of PCR reaction was $25 \mu \mathrm{L}$ and consisted of $11.2 \mu \mathrm{L}$ of nuclease-free water, 0.4 of each primer $(10 \mu \mathrm{M}), 7 \mu \mathrm{L}$ of My Taq ${ }^{\text {TM }}$ HS Red Mix (BioLine, USA) and $6 \mu \mathrm{L}$ of DNA template. The PCR was performed following the profile as previously described [40].

The PCR products were purified using TIANquick Midi Purification Kit (TIANGEN BIOTEC, Beijing, China). The purified PCR products were sent to a sequencing service (Macrogen, Seoul, Korea) for direct sequencing using the same primers as those in the PCR reactions.

\subsection{Identification of Blood Meal Source by PCR-RFLP}

The $c y t b$ gene of mitochondrial DNA was amplified from the genomic DNA. The specific primers of vertebrates were used: BM1 (5'-CCCCTCAGAATGATATTTGTCCTCA$\left.3^{\prime}\right)$ and BM2 (5'-CCATCCAACATCTCAGCATGATGAAA-3') [31]. The total volume of PCR was $25 \mu \mathrm{L}$, containing $11 \mu \mathrm{L}$ of nuclease-free water, $7 \mu \mathrm{L}$ of My Taq ${ }^{\mathrm{TM}} \mathrm{HS}$ Red Mix (BioLine, Taunton, MA, USA), 0.5 of each primer $(10 \mu \mathrm{M})$ and $6 \mu \mathrm{L}$ of DNA template. The reaction was performed in a thermal cycler (Eppendorf, Hamburg, Germany) following the 
PCR profile [41]. The PCR products sized $358 \mathrm{bp}$ were obtained and used for blood meal source analysis by restriction fragment length polymorphism (RFLP) technique. The PCR products were cut at the specific site by restriction enzymes Hae III, Rsa I and Aci I (Thermo Fisher scientific, Inc., Waltham, MA, USA). PCR product digestion was performed in a total volume of $30 \mu \mathrm{L}$ containing $17 \mu \mathrm{L}$ of nuclease free water, $10 \mu \mathrm{L}$ of PCR product, $2 \mu \mathrm{L}$ of 10X FastDigest Green Buffer, $1 \mu \mathrm{L}$ of FastDigest enzyme and $10 \mu \mathrm{L}$ of PCR product, and then incubated at $37^{\circ} \mathrm{C}$ for $5 \mathrm{~min}$. The digested PCR product was loaded onto $1.5 \%$ agarose gel for fragment size evaluation alongside a molecular weight marker (BioLine, Taunton, MA, USA). The expected fragments of $c y t b$ PCR products digested by endonuclease enzymes Hae III, Rsa I and Aci I [31] are shown in Table 1 and used for blood meal source identification. The patterns of digested DNA fragments of the three endonuclease enzymes in each blood meal source show distinct differences.

Table 1. The DNA fragments size (bp) of cyt $b$ PCR products cleaved by three endonuclease enzymes.

\begin{tabular}{cccc}
\hline \multirow{2}{*}{ Blood Meal Sources } & \multicolumn{3}{c}{ Fragments Size (bp) } \\
\cline { 2 - 4 } & Hae III & Rsa I & Aci I \\
\hline Homo sapiens (Human) & 233,124 & 358 & $189,113,55$ \\
Canis familiaris (Dog) & 358 & 358 & 358 \\
Rattus novergicus (Rats) & 358 & $267,59,31$ & 358 \\
Felis catus (Domestic cats) & $272,74,11$ & $214,119,24$ & 244,113 \\
Sus domesticus (Swine) & $153,130,74$ & 358 & 358 \\
Bus Taurus (Cattle) & $159,124,74$ & $322,31,4$ & 358 \\
Gallus gallus (Chicken) & $159,124,74$ & 208,149 & 308,49 \\
Equus caballus (Horse) & $159,124,74$ & 358 & 244,113 \\
\hline
\end{tabular}

\subsection{Phylogenetic Analysis of Sand Fly Species and Detected Parasites}

The DNA sequences of sand flies and Trypanosoma were checked for ambiguous base calls and assembled by BioEdit version 7.2 .5 [42]. The assembly sequences were compared to the GenBank database using BLASTn tool (https:/ /blast.ncbi.nlm.nih.gov/ Blast.cgi accessed on 9 November 2021). Phylogenetic trees were constructed by the maximum likelihood (ML) method using Molecular Evolutionary Genetics Analysis version 6.0 (MEGA 6.0) software [43].

\section{Results}

\subsection{Collection and Morphological Identification of Sand Flies}

A total of 384 sand flies were collected from localities in Phang-Nga, Satun, Songkhla and Surat Thani provinces. Of these, 155 blood-fed females were selected for Leishmania spp. and Trypanosoma spp. detection and blood meal source analysis. The highest number of blood-fed females was collected from Satun in a Buddha cave (69 individuals, $44.5 \%$ ) and in the vicinity of rural settlements (46 individuals, $29.68 \%$ ), followed by collections near rural settlements from Songkhla, Phang-Nga, and Surat Thani, with 24 (15.48\%), $11(7.10 \%)$ and $5(3.23 \%)$ individuals, respectively. These sand flies were classified in the genera Idiophlebotomus, Phlebotomus and Sergentomyia. Based on morphological characteristics, twelve species were identified: Idiophlebotomus asperulus $(n=19)$, P. stantoni $(n=4)$, P. argentipes $(n=3)$, S. anodontis $(n=20)$, S. barraudi $(n=9)$, S. hamidi $(n=23)$, S. hodgsoni $(n=4)$, S. hodgsoni hodgsoni $(n=32)$, S. indica $(n=5)$, S. iyengari $(n=2), S$. khawi $(n=17), S$. silvatica $(n=11)$ and Sergentomyia sp. $(n=6)$. The dominant species in this study was $S$. hodgsoni hodgsoni, which was found only in one cave in Satun province (Table 2). 
Table 2. Morphological identification and blood meal source analysis of blood-fed female sand flies.

\begin{tabular}{|c|c|c|c|c|c|c|c|c|c|}
\hline \multirow{2}{*}{ Sand Fly Species } & \multicolumn{6}{|c|}{ No. of Sand Flies in Collection Sites } & \multicolumn{3}{|c|}{ Blood Meal Source } \\
\hline & SKA & SNI & STN1 & STN2 & PNA & Total & Human & Dog & Rat \\
\hline Id. asperulus & 0 & 2 & $5^{(1)}$ & 5 & $7^{(1)}$ & 19 & 3 & 0 & 0 \\
\hline P. argentipes & 1 & 0 & 1 & 1 & 0 & 3 & 2 & 0 & 1 \\
\hline P. stantoni & 2 & 0 & 1 & 1 & 0 & 4 & 0 & 0 & 0 \\
\hline S. anodontis & 0 & 3 & 8 & 8 & 1 & 20 & 2 & 0 & 1 \\
\hline S. barraudi & 2 & 0 & $5^{(2)}$ & 2 & 0 & 9 & 2 & $1^{(1)}$ & 0 \\
\hline S. hamidi & 0 & 0 & 19 & 4 & 0 & 23 & 7 & 0 & 0 \\
\hline S. hodgsoni & 0 & 0 & 2 & 1 & 1 & 4 & 2 & 0 & 0 \\
\hline S. hodgsoni hodgsoni & 0 & 0 & 0 & 32 & 0 & 32 & 4 & 8 & 11 \\
\hline S. indica & $4^{(1)}$ & 0 & 0 & 1 & 0 & 5 & 0 & 0 & 0 \\
\hline S. iyengari & 0 & 0 & 1 & 1 & 0 & 2 & 0 & 0 & 0 \\
\hline S. khawi & $14^{(2)}$ & 0 & 2 & 0 & 1 & 17 & 2 & 0 & 0 \\
\hline S. silvatica & 0 & 0 & 1 & 10 & 0 & 11 & 7 & 0 & 1 \\
\hline Sergentomyia sp. & 1 & 0 & 1 & $3^{(1)}$ & 1 & 6 & $2^{(1)}$ & 0 & 0 \\
\hline Total & 24 & 5 & 46 & 69 & 11 & 155 & 33 & 9 & 14 \\
\hline
\end{tabular}

Collection sites near rural settlements in Songkhla province (SKA), Surat Thani province (SNI), Satun province (STN1), Pang-Nga province (PNA) and in a Buddha cave in Satun province (STN2). Superscripted numbers with parentheses represent the number of sand flies infected by Trypanosoma sp.

\subsection{Detection of Leishmania and Trypanosoma spp. in Sand Flies}

Screening of the genomic DNA of all 155 engorged females for Leishmania DNA by PCR amplification of ITS1 region provided eight positive samples (5.16\%). Four of them were detected in samples from Satun province (ST43, ST134, ST143 and ST139), three from Songkhla province (SK97, SK109 and SK91) and one (PN71) from Pang-Nga province. ITS1 sequences obtained were compared with sequences from GenBank by nucleotide BLAST (blastn) search analysis, showing unexpectedly best match with Trypanosoma spp. rather than Leishmania spp. Phylogenetic analysis of ITS1 sequences by the maximum likelihood (ML) method showed that sequence LSK97 group together with Trypanosoma congolense, T. rangeli and T. lewisi, while the sequences LSK91 and LPN71 were closely related to Trypanosoma minasense (AB362411), and the sequence LST143 is closely related to Trypanosoma avium (AY929322) in Clade A. The samples LSK91, LSK97, LPN71 and LST143 showed low sequence identity $(<50 \%)$ with their closest strains; therefore, the sequences LSK91, LSK97, LPN71 and LST143 were identified as Trypanosoma sp. based on ITS1 region (Figure 2). When considering the sequences in Clade B, samples LSK109, LST43, LST134 and LST139 group together with Trypanosoma sp. (KJ467211) with 62\% bootstrap (Figure 1). The sequence LST 43 showed $86.8 \%$ sequence similarity to Trypanosoma sp. (KJ467211), while other samples in Clade B showed very low sequence similarity to Trypanosoma sp. (KJ467211) in the range of 48-55\%. Therefore, the sequences LSK109, LST43, LST134 and LST139 were identified as Trypanosoma sp. The ITS1 sequences of Trypanosoma sp. in this study were deposited in the GenBank database under the accession number OL332783-OL332790.

\subsection{Molecular Identification of Trypanosoma-Positive Sand Flies}

Species identity of eight Trypanosoma-positive sand flies was confirmed using PCR amplification and sequencing analysis of COI gene. The phylogenetic tree was constructed based on COI gene sequences of sand flies and related sand fly sequences derived from the GenBank and BOLD databases using the ML method with 1000 replicates of bootstrapping. Based on the sequences obtained, four species with high sequence similarity (99.8-100\%) were identified: S. barraudi (ST143), S. indica (SK91), S. khawi (SK97, SK109) and Id. asperulus (ST134, PN71). Two samples (ST43 and ST139) were identified as Sergentomyia sp. with no species designation due to lack of reference sequences (Figure 3). These two sand flies were suspected to be novel species. The partial COI gene sequences of sand fly sequences were deposited in GenBank with the accession number OK576207-OK576214. 


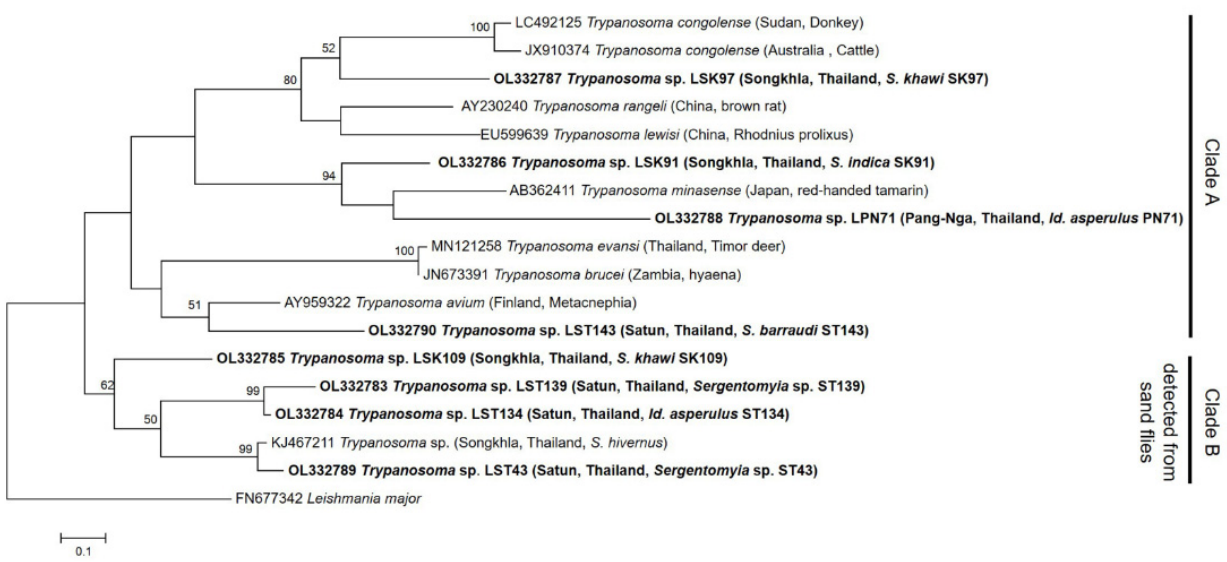

Figure 2. Maximum likelihood phylogenetic tree of Trypanosoma ITS1 region sequences. Leishmania major (FN677342) was used as root of tree. The number on the node represents bootstrap value (\%) derived from 1000 replicates. The scale bar represents 0.1 nucleotide substitutions per site.

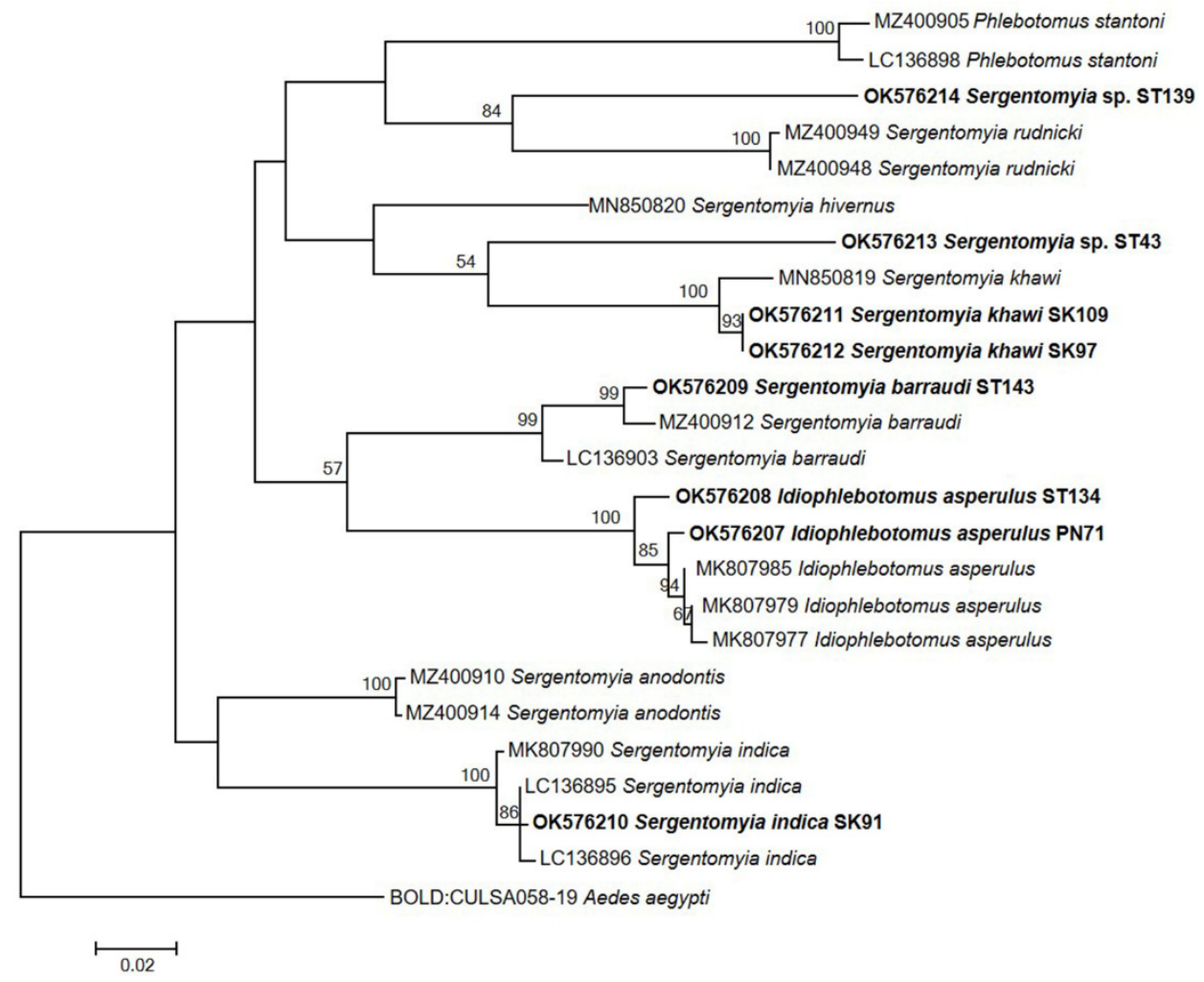

Figure 3. Phylogenetic tree analysis of $563 \mathrm{bp}$ sand fly COI gene sequences using the maximum likelihood method. Bootstrap values above $50 \%$ derived from 1000 replication are shown on branches. The scale bar represents 0.02 nucleotide substitutions per site. Bold letters indicate samples from this study. The COI gene sequence of Aedes aegypti (BOLD: CULSA058-19) from the BOLD database was used as root of tree.

\subsection{Identification of Blood Source by RFLP}

The genomic DNA of all 155 blood-fed females was used as a template for the amplification of the $c y t b$ gene followed by RFLP assay. The 358 bp PCR product was successfully amplified (Figure 4a) for 56 samples (36.13\%): 50 of Sergentomyia spp., 3 of Id. asperulus and 3 of $P$. argentipes. RFLP patterns revealed that human was the main blood meal source, as it was detected in 33 samples, followed by rat and dog blood identified in 14 and 9 samples, respectively (Table 2). Briefly, the restriction pattern for cyt $b$ PCR products of human blood samples by Hae III endonuclease produced bands of 233 and 124 bp, while in the case of 
PCR products of dog and rat blood samples, no cleavage site was found. The pattern of rat DNA digested by $R s a$ I generated fragments with sizes of 267, 59, 31 bp, whereas the restriction site on $c y t b$ PCR product from human and dog samples was not found. The fragment pattern of human DNA digested by Aci I resulted in fragments of 189, 113, $55 \mathrm{bp}$. Dog and rat DNA samples were not digested by Aci I (Table 1). No mixed blood meals were identified. Human was the most often detected host for S. hamidi and S. silvatica. The fragment of $c y t b$ gene could not be amplified from blood-fed P. stantoni, S. indica and S. iyengari. Of eight Trypanosoma-positive sand flies, blood source of only two samples (ST43 and ST143) was successfully determined (Figure 4b), while for six remaining samples (SK91, SK97, SK109, ST134, ST139 and PN71) amplification of the cyt $b$ gene fragment failed. Based on the RFLP patterns of samples ST43 and ST143, the source of blood was determined as human and dog, respectively.

a

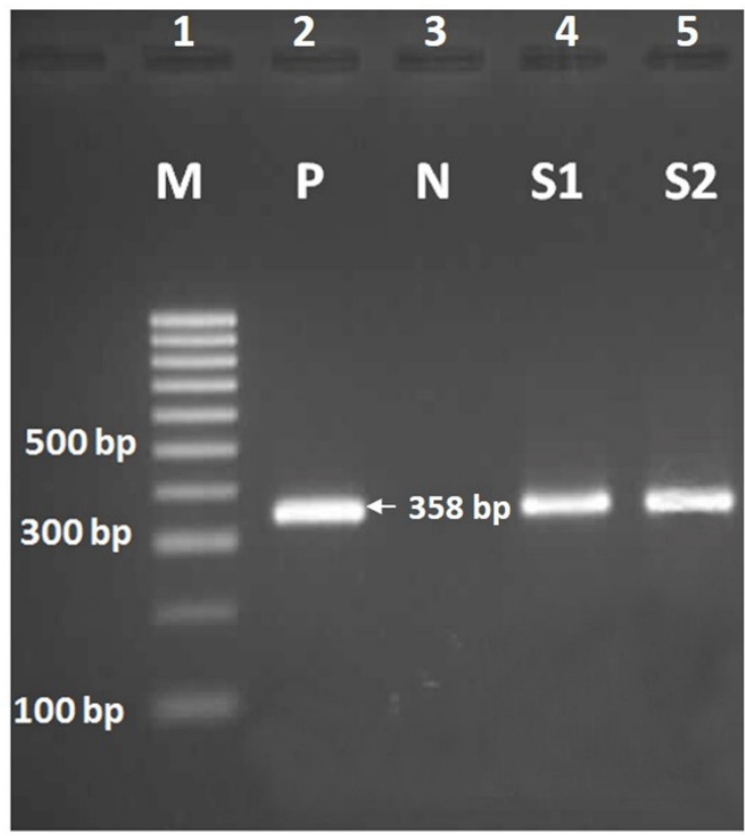

b

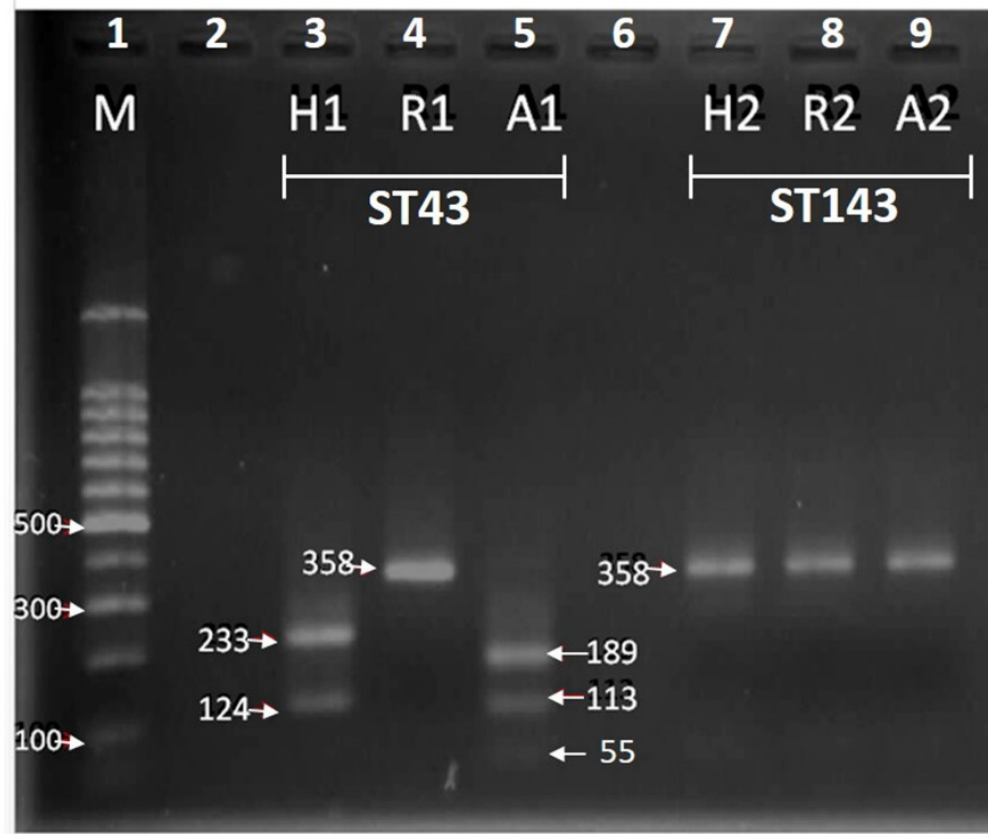

Figure 4. (a) Polymerase Chain Reaction (PCR) amplification of vertebrate DNA from Trypanosoma sp. infected blood-fed female sand flies using the cytochrome b (cyt b) gene. Lane 1: $100 \mathrm{bp}$ molecular weight marker (BioLine, USA), Lane 2: positive control (genomic DNA of human blood), Lane 3: negative control $\left(\mathrm{ddH}_{2} \mathrm{O}\right)$, Lane 4-5: genomic DNA of blood-fed female sand flies S1 and S2 represented sample code ST43 and ST143, respectively. (b) Electrophoresis of partially amplified $c y t b$ gene fragments $(358 \mathrm{bp}$ ) from vertebrate host of Trypanosoma sp. infected blood-fed female sand flies digested with restriction enzymes Hae III, Rsa I and Aci I. Lane 1: $100 \mathrm{bp}$ molecular weight marker (BioLine, Taunton, MA, USA), Lane 3-5: sample ST43 digested by Hae III, Rsa I and Aci I, respectively. Lane 7-9: sample ST143 digested by Hae III, Rsa I and Aci I, respectively.

\section{Discussion}

In this study, twelve sand fly species, namely Idiophlebotomus asperulus, P. stantoni, P. argentipes, S. anodontis, S. barraudi, S. hamidi, S. hodgsoni, S. hodgsoni hodgsoni, S. indica, S. iyengari, S. khawi, S. silvatica and Sergentomyia sp. were collected from Phang-Nga, Satun, Songkhla and Surat Thani provinces, which are regions so far endemic for human leishmaniasis. All eleven sand fly species except $S$. hodgsoni hodgsoni were found in rural settlements. In contrast, $S$. hodgsoni hodgsoni was the most abundant species specifically found in a Buddha cave in Satun province, while $S$. khawi was not found in any cave. This finding agrees with earlier work suggesting that $S$. hodgsoni hodgsoni is the most common species collected from caves in Kanchanaburi province, Thailand [44], so we confirm that it 
is indeed a cavernicolous species. The rest of the identified sand fly species were collected from both rural settlements and caves. The presence of 12 species at the studied localities comprises nearly half of all sand fly species reported in Thailand so far. In general, sand fly fauna in Thailand is still not fully investigated and rather poorly documented. The last published checklist includes 26 species of four genera [44], but later records and taxonomical reassessments added several more species such as S. hivernus [25] or S. raynali [45]. We may expect that future research that combines complementary morphological and molecular approaches will provide further insight into the true local diversity, and potentially may lead to recognition and taxonomical description of new species of sand flies in Thailand. As some species seem to be cave-dwellers, special attention will be given to vast cavernicolous habitats which remain largely unexplored and may reveal a score of so far undescribed species.

Sequencing analysis of vertebrate mitochondrial cytochrome $b$ gene has been widely used to identify blood sources of various hematophagous insects, including sand flies [46]. In our study, we deployed this approach to successfully identify blood meals in approximately one-third of engorged females collected. This success rate reflects the fact that amplification of the host gene is difficult in later stages of blood meal digestion due to the negative effect of progressing digestive enzymes. This shortcoming could be overcome in future studies by the deployment of protein-based MALDI-TOF peptide mapping that has recently been demonstrated to also allow successful blood identification in blood meals with more advanced blood digestion [47]. In our study, humans were the major blood meal source of sand flies, followed by rats and dogs. No mixed blood meals were detected. Several species demonstrated opportunistic feeding behavior: blood of two or even three hosts were detected in different females of P. argentipes, S. anodontis, S. barraudi, S. silvatica and S. hodgsoni hodgsoni. This S. hodgsoni hodgsoni which, despite its exclusive occurrence in a cavernicolous habitat, was demonstrated to feed on dogs, humans and rats alike. As sand flies are generally regarded as rather poor fliers with limited range of host seeking, we may assume that they readily bite occasional human visitors of the caves. Moreover, humans were the most preferred hosts of S. silvatica and S. hamidi, although the low number of analyzed females does not allow credible assumptions about the anthropophily of these species. Blood meal analysis of females identified as S. khawi, S. indica and Id. asperulus that were shown to harbor DNA of Trypanosoma sp. unfortunately failed to provide identification of their blood meals, thus not providing any insight regarding the potential involvement of these three species in the transmission of these protozoans.

Hematophagous sand fly females serve as vectors of different pathogens, most importantly protozoans of the genus Leishmania that cause disease with varying clinical outcomes. Albeit Thailand is traditionally not regarded as a country heavily burdened by human leishmaniases, numbers of autochthonous cases increased in the last six decades, and four Leishmania species were recorded as their causative agents. So far, none of the sand fly species naturally occurring in the country were conclusively proven as a vector; however, various sand flies of the genera Sergentomyia spp. and Phlebotomus spp. are suspected vectors, since Leishmania DNA was detected by PCR assays within the field-collected specimens of these species: DNA of L. martiniquensis has been detected in S. khawi [2], and DNA of L. siamensis (later synonymized with L. martiniquensis) in S. gemmea, S. barraudi and S. iyengari $[17,18,48]$. In this study, we did not detect Leishmania DNA in any of 155 analyzed specimens. This correlates with a previous study from Satun province, which did not detect any Leishmania DNA in field-collected specimens of P. stantoni, P. argentipes, S. gemmea, $S$. indica, S. barraudi, S. iyengari, S. bailyi, S. perturbans and S. silvatica [49].

Besides Leishmania, which is the most important sand fly-borne parasitic protozoan, sporadic infections of Trypanosoma spp. were previously reported in Phlebotomus spp. [50] and Sergentomyia spp. [51] from various geographical regions. In Thailand, Trypanosoma sp. was recently detected in a single specimen of P. stantoni [25], while another study detected T. noyesi in S. anodontis and P. asperulus and another yet undescribed Trypanosoma sp. in these two sand fly species, along with P. betisi collected in endemic and nonendemic 
leishmaniasis areas in southern Thailand [2]. The results from our study correlate to those detected Trypanosoma sp. infected $I d$. asperulus, and may indicate the potential transmitter of Trypanosoma spp. in Thailand, as recently reported in terms of an infected Trypanosoma sp. found in S. barraudi, S. indica and S. khawi. Trypanosoma sp. LST43 detected in Sergentomyia sp. from Satun province in the current study belongs to Trypanosoma sp. (KJ467211) sequence from GenBank database with high sequence identity. Trypanosoma sp. (KJ467211) DNA was detected in P. stantoni from Songkhla province, southern Thailand [25]. From this result, we conclude that two sequences of Trypanosoma sp. LST43 may be the same species as Trypanosoma sp. (KJ467211). Although to date no human cases of trypanosomiasis were reported in Thailand so far, trypanosomiasis caused by Trypanosoma evansi and Trypanosoma lewisi were reported in animals [52,53]. Thus, precise species identification of sand fly-borne Trypanosoma spp. and further assessment of the potential role of different sand fly species as their vectors remain important factors to consider for adequate prevention planning. The specific primer for species-level identification of Trypanosoma spp. will be designed in our future work.

\section{Conclusions}

This study reports for the first time a detection of Trypanosoma sp. DNA in Sergentomyia barraudi, S. indica and S. khawi in Thailand, suggesting that several Trypanosoma spp. may circulate in natural and rural habitats with domestic canines serving as reservoirs. The analysis of blood meals in engorged females provides new data about blood sources for nine sand fly species, showing opportunistic feeding habits of some, and the utilization of human blood by several, including the cavernicolous species S. hodgsoni hodgsoni.

Author Contributions: Conceptualization, T.P.; methodology, T.P.; software, J.B.; validation, T.P. and J.B.; formal analysis, J.B.; investigation, T.P., K.T., A.T. and S.K.; resources, T.P.; data curation, T.P.; writing-original draft preparation, J.B.; writing—review and editing, T.P., P.S. and V.D.; visualization, J.B.; supervision, T.P.; project administration, T.P.; funding acquisition, T.P. and P.S. All authors have read and agreed to the published version of the manuscript.

Funding: This research was supported by Prince of Songkla University and the Ministry of Higher Education, Science, Research and Innovation under the Reinventing University Project (Grant Number REV64032), and The Program Management Unit for Human Resources and Institutional Development, Research and Innovation-CU (Grant No. B16F630071), Thailand Science Research Innovation (TSRI)CU (Grant No. FRB640001).

Institutional Review Board Statement: The animal study protocol was approved by Ethics Committee of the Institutional Animal Care, Prince of Songkla University (Approval No. 2561-10-021 and dated 11 June 2018).

Data Availability Statement: All the associated data are available in the manuscript.

Acknowledgments: We would like to thank the Office of Disease Prevention and Control, Region 11 Nakhon Si Thammarat province, Thailand, for fieldwork support, and the Faculty of Medical Technology, Prince of Songkla University, for providing laboratory workspace and equipment. We wish also to thank Napadol Sudsom from the Nan Provincial Public Health Office, Ministry of Public Health, Thailand, for the generation of sampling sites on the map of Thailand.

Conflicts of Interest: The authors declare no conflict of interest.

\section{References}

1. Rêgo, F.D.; Rugani, J.M.N.; Shimabukuro, P.H.F.; Tonelli, G.B.; Quaresma, P.F.; Gontijo, C.M.F. Molecular Detection of Leishmania in Phlebotomine Sand Flies (Diptera: Psychodidae) from a Cutaneous Leishmaniasis Focus at Xakriabá Indigenous Reserve, Brazil. PLoS ONE 2015, 10, e0122038. [CrossRef]

2. Srisuton, P.; Phumee, A.; Sunantaraporn, S.; Boonserm, R.; Sor-Suwan, S.; Brownell, N.; Pengsakul, T.; Siriyasatien, P. Detection of Leishmania and Trypanosoma DNA in Field-Caught Sand Flies from Endemic and Non-Endemic Areas of Leishmaniasis in Southern Thailand. Insects 2019, 10, 238. [CrossRef] [PubMed] 
3. Ferreira, R.C.; De Souza, A.A.; Freitas, R.A.; Campaner, M.; Takata, C.S.A.; Barrett, T.V.; Shaw, J.J.; Teixeira, M.M.G. A Phylogenetic Lineage of Closely Related Trypanosomes (Trypanosomatidae, Kinetoplastida) of Anurans and Sand Flies (Psychodidae, Diptera) Sharing the Same Ecotopes in Brazilian Amazonia. J. Eukaryot. Microbiol. 2008, 55, 427-435. [CrossRef] [PubMed]

4. Calzolari, M.; Rugna, G.; Clementi, E.; Carra, E.; Pinna, M.; Bergamini, F.; Fabbi, M.; Dottori, M.; Sacchi, L.; Votypka, J. Isolation of a Trypanosome Related to Trypanosoma theileri (Kinetoplastea: Trypanosomatidae) from Phlebotomus perfiliewi (Diptera: Psychodidae). BioMed Res. Int. 2018, 2018, 2597074. [CrossRef]

5. World Health Organization. Global Leishmaniasis Surveillance: 2019-2020, a Baseline for the 2030 Roadmap. Wkly. Epidemiol. Rec. 2021, 96, 401-419.

6. Sarasombath, P.T. Leishmaniasis: An Evolving Public Health Concern in Thailand. Siriraj Med. J. 2018, 70, 363-376.

7. Jariyapan, N.; Daroontum, T.; Jaiwong, K.; Chanmol, W.; Intakhan, N.; Sor-suwan, S.; Siriyasatien, P.; Somboon, P.; Bates, M.D.; Bates, P.A. Leishmania (Mundinia) orientalis n. sp. (Trypanosomatidae), a Parasite from Thailand Responsible for Localised Cutaneous Leishmaniasis. Parasit. Vectors 2018, 11, 351. [CrossRef]

8. Kongkaew, W.; Siriarayaporn, P.; Leelayoova, S.; Supparatpinyo, K.; Areechokchai, D.; Duang-ngern, P.; Chanachai, K.; Sukmee, T.; Samung, Y.; Sridurongkathum, P. Autochthonous Visceral Leishmaniasis: A Report of a Second Case in Thailand. Southeast Asian J. Trop. Med. Public Health 2007, 38, 8-12.

9. Maharom, P.; Siripattanapipong, S.; Mungthin, M.; Naaglor, T.; Sukkawee, R.; Pudkorn, R.; Wattana, W.; Wanachiwanawin, D.; Areechokchai, D.; Leelayoova, S. Visceral Leishmaniasis Caused by Leishmania infantum in Thailand. Southeast Asian J. Trop. Med. Public Health 2008, 39, 988-990.

10. Bualert, L.; Charungkiattikul, W.; Thongsuksai, P.; Mungthin, M.; Siripattanapipong, S.; Khositnithikul, R.; Naaglor, T.; Ravel, C.; El Baidouri, F.; Leelayoova, S. Autochthonous Disseminated Dermal and Visceral Leishmaniasis in an AIDS Patient, Southern Thailand, Caused by Leishmania siamensis. Am. J. Trop. Med. Hyg. 2012, 86, 821-824. [CrossRef]

11. Suankratay, C.; Suwanpimolkul, G.; Wilde, H.; Siriyasatien, P. Autochthonous Visceral Leishmaniasis in a Human Immunodeficiency Virus (HIV)-Infected Patient: The First in Thailand and Review of the Literature. Am. J. Trop. Med. Hyg. 2010, 82, 4-8. [CrossRef] [PubMed]

12. Siriwardana, Y.; Deepachandi, B.; Gunasekara, C.; Warnasooriya, W.; Karunaweera, N.D. Leishmania donovani Induced Cutaneous Leishmaniasis: An Insight into Atypical Clinical Variants in Sri Lanka. J. Trop. Med. 2019, 4538597. [CrossRef] [PubMed]

13. Svobodova, M.; Alten, B.; Zídková, L.; Dvorak, V.; Hlavacková, J.; Myskova, J.; Seblova, V.; Erisoz Kasap, O.; Belen, A.S.; Votypka, J.; et al. Cutaneous Leishmaniasis Caused by Leishmania infantum and Transmitted by Phlebotomus tobbi. Int. J. Parasitol. 2009, 39, 251-256. [CrossRef] [PubMed]

14. Chusri, S.; Hortiwakul, T.; Silpapojakul, K.; Siriyasatien, P. Consecutive Cutaneous and Visceral Leishmaniasis Manifestations Involving a Novel Leishmania Species in Two HIV Patients in Thailand. Am. J. Trop. Med. Hyg. 2012, 87, 76-80. [CrossRef]

15. Alcover, M.M.; Rocamora, V.; Guillén, M.C.; Berenguer, D.; Cuadrado, M.; Riera, C.; Fisa, R. Case Report: Diffuse Cutaneous Leishmaniasis by Leishmania infantum in a Patient Undergoing Immunosuppressive Therapy: Risk Status in an Endemic Mediterranean Area. Am. J. Trop. Med. Hyg. 2018, 98, 1313-1316. [CrossRef] [PubMed]

16. Pothirat, T.; Tantiworawit, A.; Chaiwarith, R.; Jariyapan, N.; Wannasan, A.; Siriyasatien, P.; Supparatpinyo, K.; Bates, M.D.; Kwakye-Nuako, G.; Bates, P.A. First Isolation of Leishmania from Northern Thailand: Case Report, Identification as Leishmania martiniquensis and Phylogenetic Position within the Leishmania enriettii Complex. PLoS Negl. Trop. Dis. 2014, 8, e3339. [CrossRef]

17. Kanjanopas, K.; Siripattanapipong, S.; Ninsaeng, U.; Hitakarun, A.; Jitkaew, S.; Kaewtaphaya, P.; Tan-ariya, P.; Mungthin, M.; Charoenwong, C.; Leelayoova, S. Sergentomyia (Neophlebotomus) gemmea, a Potential Vector of Leishmania siamensis in Southern Thailand. BMC Infect. Dis. 2013, 13, 333. [CrossRef]

18. Siripattanapipong, S.; Leelayoova, S.; Ninsaeng, U.; Mungthin, M. Detection of DNA of Leishmania siamensis in Sergentomyia (Neophlebotomus) iyengari (Diptera: Psychodidae) and Molecular Identification of Blood Meals of Sand Flies in an Affected Area, Southern Thailand. J. Med. Entomol. 2018, 55, 1277-1283. [CrossRef]

19. Johnson, P.D. A Case of Infection by Trypanosoma lewisi in a Child. Trans. R. Soc. Trop. Med. Hyg. 1933, 26, 467-468. [CrossRef]

20. Sarataphan, N.; Vongpakorn, M.; Nuansrichay, B.; Autarkool, N.; Keowkarnkah, T.; Rodtian, P.; Stich, R.W.; Jittapalapong, S. Diagnosis of a Trypanosoma lewisi-like (Herpetosoma) Infection in a Sick Infant from Thailand. J. Med. Microbiol. 2007, 56, 1118-1121. [CrossRef]

21. Verma, A.; Manchanda, S.; Kumar, N.; Sharma, A.; Goel, M.; Banerjee, P.S.; Garg, R.; Singh, B.P.; Balharbi, F.; Lejon, V.; et al Trypanosoma lewisi or T. lewisi-like Infection in a 37-Day-Old Indian Infant. Am. J. Trop. Med. Hyg. 2011, 85, 221-224. [CrossRef] [PubMed]

22. Van Vinh Chau, N.; Buu Chau, L.; Desquesnes, M.; Herder, S.; Phu Huong Lan, N.; Campbell, J.I.; Van Cuong, N.; Yimming, B.; Chalermwong, P.; Jittapalapong, S.; et al. A Clinical and Epidemiological Investigation of the First Reported Human Infection With the Zoonotic Parasite Trypanosoma evansi in Southeast Asia. Clin. Infect. Dis. 2016, 62, 1002-1008. [CrossRef] [PubMed]

23. Srikijkasemwat, K.; Kaewhom, P. Prevalence and Genetic Diversity of Trypanosoma evansi Infection Causing Abortion among Cattles and Buffaloes in Eastern Border Area of Thailand-Cambodia. Int. J. Agric. Technol. 2019, 15, 1021-1032.

24. Kamyingkird, K.; Chalermwong, P.; Saechan, V.; Kaewnoi, D.; Desquesnes, M.; Ngasaman, R. Investigation of Trypanosoma evansi Infection in Bullfighting Cattle in Southern Thailand. Vet. World 2020, 13, 1674-1678. [CrossRef] 
25. Phumee, A.; Tawatsin, A.; Thavara, U.; Pengsakul, T.; Thammapalo, S.; Depaquit, J.; Gay, F.; Siriyasatien, P. Detection of an Unknown Trypanosoma DNA in a Phlebotomus stantoni (Diptera: Psychodidae) Collected From Southern Thailand and Records of New Sand Flies With Reinstatement of Sergentomyia hivernus Raynal \& Gaschen, 1935 (Diptera: Psychodidae). J. Med. Entomol. 2017, 54, 429-434. [CrossRef]

26. Alexandre, J.; Sadlova, J.; Lestinova, T.; Vojtkova, B.; Jancarova, M.; Podesvova, L.; Yurchenko, V.; Dantas-Torres, F.; Brandão-Filho, S.P.; Volf, P. Experimental Infections and Co-Infections with Leishmania braziliensis and Leishmania infantum in Two Sand Fly Species, Lutzomyia migonei and Lutzomyia longipalpis. Sci. Rep. 2020, 10, 3566. [CrossRef]

27. Rogers, M.; Chance, M.; Bates, P. The Role of Promastigote Secretory Gel in the Origin and Transmission of the Infective Stage of Leishmania mexicana by the Sandfly Lutzomyia longipalpis. Parasitology 2002, 124, 495-507. [CrossRef]

28. De Colmenares, M.; Portús, M.; Botet, J.; Dobaño, C.; Gállego, M.; Wolff, M.; Seguí, G. Identification of Blood Meals of Phlebotomus perniciosus (Diptera: Psychodidae) in Spain by a Competitive Enzyme-Linked Immunosorbent Assay Biotin/Avidin Method. J. Med. Entomol. 1995, 32, 229-233. [CrossRef]

29. Bongiorno, G.; Habluetzel, A.; Khoury, C.; Maroli, M. Host Reference of Phlebotomine Sand Flies at a Hypodermic Focus of Canine Leishmaniosis in Central Italy. Acta Trop. 2003, 88, 109-116. [CrossRef]

30. Kent, R.J. Molecular Methods for Arthropod Bloodmeal Identification and Applications to Ecological and Vector-Borne Disease Studies. Mol. Ecol. Resour. 2009, 9, 4-18. [CrossRef]

31. Soares, V.Y.R.; da Silva, J.C.; da Silva, K.R.; Pires e Cruz, M.D.S.; Santos, M.P.D.; Ribolla, P.E.M.; Alonso, D.P.; Coelho, L.F.L.; Costa, D.L.; Costa, C.H.N. Identification of Blood Meal Sources of Lutzomyia longipalpis Using Polymerase Chain Reaction-Restriction Fragment Length Polymorphism Analysis of the Cytochrome B Gene. Mem. Inst. Oswaldo Cruz 2014, 109, 379-383. [CrossRef] [PubMed]

32. Quaresma, P.F.; Carvalho, G.M.; Ramos, M.C.; Andrade Filho, J.D. Natural Leishmania sp. Reservoirs and Phlebotomine Sandfly Food Source Identification in Ibitipoca State Park, Minas Gerais, Brazil. Mem. Inst. Oswaldo Cruz 2012, 107, 480-485. [CrossRef] [PubMed]

33. González, E.; Gállego, M.; Molina, R.; Abras, A.; Alcover, M.M.; Ballart, C.; Fernández, A.; Jiménez, M. Identification of Blood Meals in Field Captured Sand Flies by a PCR-RFLP Approach Based on Cytochrome b Gene. Acta Trop. 2015, 152, 96-102. [CrossRef] [PubMed]

34. Anderson, L.E. Hoyer's Solution as a Rapid Permanent Mounting Medium for Bryophytes. Bryol. 1954, 57, 242-244. [CrossRef]

35. Lewis, D.J. The Phlebotomine Sandflies (Diptera: Psychodidae) of the Oriental Region. Bull. Br. Mus. Nat. Hist. B Entomol. 1978, 37, 217-343. [CrossRef]

36. Lane, R.P. Sandflies (Phlebotominae). In Medical Insects and Arachnids; Lane, R.P., Crosskey, R.W., Eds.; Springer: Dordrecht, The Netherlands, 1993; pp. 78-119. [CrossRef]

37. Abonnenc, E. Les Phlébotomes de la Région Éthiopienne (Diptera, Psychodidae); Memoirs ORSTOM: Paris, France, $1972 ;$ Volume 1.

38. Kakarsulemankhel, J. Taxonomic Morphology of Sergentomyia (Neophlebotomus) hodgsoni hodgsoni Sinton (1933) (Diptera, Psychodidae) from Pakistan. Pak. J. Biol. Sci. 2004, 7, 1148-1153. [CrossRef]

39. Hajibabaei, M.; Janzen, D.H.; Burns, J.M.; Hallwachs, W.; Hebert, P.D.N. DNA Barcodes Distinguish Species of Tropical Lepidoptera. Proc. Natl. Acad. Sci. USA 2006, 103, 968-971. [CrossRef]

40. Spanakos, G.; Piperaki, E.-T.; Menounos, P.G.; Tegos, N.; Flemetakis, A.; Vakalis, N.C. Detection and Species Identification of Old World Leishmania in Clinical Samples Using a PCR-Based Method. Trans. R. Soc. Trop. Med. Hyg. 2008, 102, 46-53. [CrossRef]

41. Oshaghi, M.A.; Chavshin, A.R.; Vatandoost, H. Analysis of Mosquito Bloodmeals Using RFLP Markers. Exp. Parasitol. 2006, 114, 259-264. [CrossRef]

42. Hall, T.A. BioEdit: A User-Friendly Biological Sequence Alignment Editor and Analysis Program for Windows 95/98/NT. Nucleic Acids Symp. Ser. 1999, 41, 95-98.

43. Tamura, K.; Stecher, G.; Peterson, D.; Filipski, A.; Kumar, S. MEGA6: Molecular Evolutionary Genetics Analysis Version 6.0. Mol. Biol. Evol. 2013, 30, 2725-2729. [CrossRef] [PubMed]

44. Apiwathnasorn, C.; Samung, Y.; Prummongkol, S.; Phayakaphon, A.; Panasopolkul, C. Cavernicolous Species of Phlebotomine Sand Flies from Kanchanaburi Province, with an Updated Species List for Thailand. Southeast Asian J. Trop. Med. Public Health 2011, 42, 1405-1409. [PubMed]

45. Depaquit, J.; Vongphayloth, K.; Siriyasatien, P.; Polseela, R.; Phumee, A.; Loyer, M.; Vol, A.; Varlot, G.; Rahola, N.; Brey, P.T.; et al. On the True Identity of Sergentomyia gemmea and Description of a Closely Related Species: Se. raynali n. sp. Med. Vet. Entomol. 2019, 33, 521-529. [CrossRef]

46. Borland, E.M.; Kading, R.C. Modernizing the Toolkit for Arthropod Bloodmeal Identification. Insects 2021, 12, 37. [CrossRef] [PubMed]

47. Hlavackova, K.; Dvorak, V.; Chaskopoulou, A.; Volf, P.; Halada, P. A Novel MALDI-TOF MS-Based Method for Blood Meal Identification in Insect Vectors: A Proof of Concept Study on Phlebotomine Sand Flies. PLoS Negl. Trop. Dis. 2019, 13, e0007669. [CrossRef]

48. Chusri, S.; Thammapalo, S.; Chusri, S.; Thammapalo, S.; Silpapojakul, K.; Siriyasatien, P. Animal Reservoirs and Potential Vectors of Leishmania siamensis in Southern Thailand. Southeast Asian J. Trop. Med. Public Health 2014, 45, 13-19.

49. Panthawong, A.; Chareonviriyaphap, T.; Phasuk, J. Species Diversity and Seasonality of Phlebotmomine Sand Flies (Diptera: Psychodidae) in Satun Province, Thailand. Southeast Asian J. Trop. Med. Public Health 2015, 46, 857-865. 
50. Kato, H.; Uezato, H.; Sato, H.; Bhutto, A.M.; Soomro, F.R.; Baloch, J.H.; Iwata, H.; Hashiguchi, Y. Natural Infection of the Sand Fly Phlebotomus kazeruni by Trypanosoma Species in Pakistan. Parasit. Vectors 2010, 3, 10. [CrossRef]

51. Nzelu, C.O.; Kato, H.; Puplampu, N.; Desewu, K.; Odoom, S.; Wilson, M.D.; Sakurai, T.; Katakura, K.; Boakye, D.A. First Detection of Leishmania tropica DNA and Trypanosoma Species in Sergentomyia Sand Flies (Diptera: Psychodidae) from an Outbreak Area of Cutaneous Leishmaniasis in Ghana. PLoS Negl. Trop. Dis. 2014, 8, e2630. [CrossRef]

52. Molee, P.W.; Sakulsak, N.; Saengamnatdej, S. Detection of Trypanosoma spp. in Bandicota Indica from the Thai-Myanmar Border Area, Mae Sot District Tak Province, Thailand. Asian Pac. J. Trop. Med. 2019, 12, 457-462. [CrossRef]

53. Pumhom, P.; Pognon, D.; Yangtara, S.; Thaprathorn, N.; Milocco, C.; Douangboupha, B.; Herder, S.; Chaval, Y.; Morand, S.; Jittapalapong, S.; et al. Molecular Prevalence of Trypanosoma spp. In Wild Rodents of Southeast Asia: Influence of Human Settlement Habitat. Epidemiol. Infect. 2014, 142, 1221-1230. [CrossRef] [PubMed] 